\title{
Bioinspired Microstructures Polymer Surfaces with Antireflective Properties ${ }^{+}$
}

\author{
Alexandre Emmanuel Wetzel 1,*, Ada-Ioana Bunea ${ }^{1}$, Einstom Engay ${ }^{1}$, Nikolaj Kofoed Mandsberg ${ }^{2}$, \\ Nuria del Castillo Iniesta ${ }^{1}$, Anja Boisen ${ }^{2}$, Kirstine Berg-Sørensen ${ }^{2}$ and Rafael Taboryski ${ }^{1}$ \\ 1 National Centre for Nano Fabrication and Characterization (DTU Nanolab), Technical University of \\ Denmark, Ørsted Plads 347, 2800 Kongens Lyngby, Denmark; awet@dtu.dk (A.E.W.); \\ adabu@dtu.dk (A.-I.B.); einen@dtu.dk (E.E.); nurin@dtu.dk (N.d.C.I.); rata@dtu.dk (R.T.) \\ 2 Department of Health Technology (DTU Health Tech), Technical University of Denmark, Ørsted Plads \\ 345C, 2800 Kongens Lyngby, Denmark; nikoma@dtu.dk (N.K.M.); aboi@dtu.dk (A.B.); kibs@dtu.dk (K.B.-S.); \\ * Correspondence: awet@dtu.dk \\ + Presented at the 1st International Conference on Micromachines and Applications, 15-30 April 2021; \\ Available online: https://micromachines2021.sciforum.net/.
}

Citation: Wetzel, A.E.; Bunea, A.-I.; Engay, E.; Mandsberg, N.K.; del Castillo Iniesta, N.; Boisen, A.; Berg-Sørensen, K.; Taboryski, R. Bioinspired Microstructures Polymer Surfaces with Antireflective Properties. Eng. Proc. 2021, 4, 15. https://doi.org/10.3390/

Micromachines2021-09548

Academic Editor: Ion Stiharu

Published: 14 April 2021

Publisher's Note: MDPI stays neutral with regard to jurisdictional claims in published maps and institutional affiliations.

Copyright: (C) 2021 by the authors. Licensee MDPI, Basel, Switzerland. This article is an open access article distributed under the terms and conditions of the Creative Commons Attribution (CC BY) license (http://creativecommons.org/licenses/by/4.0/).

\begin{abstract}
Antireflective (AR) coatings have been around for more than a century, with the simplest form dating back to Lord Rayleigh's 1886 tarnished glass. Different approaches to obtaining AR coatings exploit index-matching, interference, or absorbing phenomena. In 2002, a novel super black surface was developed by Brown et al. at the National Physical Laboratory in the UK and soon gained significant interest among both academia and industry. Since then, scientists have been competing in a race to produce the blackest material. Although extremely valuable, existing solutions usually require complicated fabrication procedures and post-application treatments. Structural colors are ubiquitous in nature, so an interesting approach to developing AR coatings is biomimicry. Moth-eye structures are well-known for their AR properties, and they have been successfully replicated using micro- and nanofabrication methods and employed as AR coatings. Interestingly, recent studies from Harvard University highlight two types of microstructures that lead to super black coloring in nature, i.e., barbule microstructures on birds of paradise and cuticular bumps on peacock spiders. These publications provide detailed information on the shape of such natural super black microstructures and mechanisms behind the observed super black effect. Although the replication of such structures should prove extremely valuable, it has not yet been demonstrated. In this paper, we present the fabrication and characterization of AR microarrays inspired by the peacock spiders' super black structures encountered in nature. Fabrication is done by super-resolution threedimensional (3D) printing using two-photon polymerization of an acrylic resin. The optical properties of microstructure arrays with different shape design parameters are then characterized using a homemade reflectance/transmittance setup, which allows wavelength-dependent investigations in the ultraviolet, visible, and near-infrared ranges. The influence of the shape design parameters on the optical properties of the microarrays is then discussed with experimental measurements as well as simulations.
\end{abstract}

Keywords: antireflective coating; super black structures; microstructures; biomimicry; 3D printing

Supplementary Materials: The following are available online at https://www.mdpi.com/article/10.3390/Micromachines2021-09548/s1.

Institutional Review Board Statement: Not applicable.

Informed Consent Statement: Not applicable.

Data Availability Statement: The data presented in this study are available on request from the corresponding author. 